\title{
Perceptual and acoustic analysis of lexical stress in Greek speakers with dysarthria
}

\author{
Ioannis Papakyritsis and Nicole Müller
}

\section{Linköping University Post Print}

\section{Tweet}

N.B.: When citing this work, cite the original article.

Original Publication:

Ioannis Papakyritsis and Nicole Müller, Perceptual and acoustic analysis of lexical stress in Greek speakers with dysarthria, 2014, Clinical Linguistics \& Phonetics, (28), 7-8, 555-572. http://dx.doi.org/10.3109/02699206.2014.926993

Copyright: Informa Healthcare http://informahealthcare.com/

Postprint available at: Linköping University Electronic Press

http://urn.kb.se/resolve?urn=urn:nbn:se:liu:diva-109597 


\title{
Perceptual and acoustic analysis of lexical stress in Greek speakers with dysarthria
}

\author{
Ioannis Papakyritsis ${ }^{1}$ and Nicole Müller ${ }^{2}$ \\ ${ }^{1}$ Western Illinois University, Macomb, IL, USA \\ ${ }^{2}$ Linköping University, Linköping, Sweden
}

(Received 4 February 2014, accepted 25 April 2014)

Address for Correspondence:

Dr. Ioannis Papakyritsis

Dept. Communication Sciences and Disorders

Western Illinois University

240 Memorial Hall, 1 University Circle

Macomb, IL 61455

I-Papakyritsis@wiu.edu 


\begin{abstract}
The study reported in this paper investigated the abilities of Greek speakers with dysarthria to signal lexical stress at the single word level. Three speakers with dysarthria and two unimpaired control participants were recorded completing a repetition task of a list of words consisting of minimal pairs of Greek disyllabic words contrasted by lexical stress location only. Fourteen listeners were asked to determine the attempted stress location for each word pair. Acoustic analyses of duration and intensity ratios, both within and across words, were undertaken to identify possible acoustic correlates of the listeners' judgments concerning stress location. Acoustic and perceptual data indicate that while each participant with dysarthria in this study had some difficulty in signaling stress unambiguously, the pattern of difficulty was different for each speaker. Further, it was found that the relationship between the listeners' judgments of stress location and the acoustic data was not conclusive.
\end{abstract}

Key words: Greek, dysarthria, lexical stress 


\section{Introduction}

The field of motor speech disorders in Greek is substantially under researched. Additionally, acoustic studies on lexical stress in dysarthria are generally very rare (Kim et al. 2010). This study examines the acoustic and perceptual effects of Greek dysarthria on lexical stress.

\section{Lexical stress in Greek}

Lexical stress refers to the relative prominence of a syllable within a word (Kim et al., 2010). This relative prominence is generally achieved by variations in intensity, duration, $\mathrm{F}_{0}$ and vowel quality. Although not all of these mechanisms are utilized in every language, most use a combination of the aforementioned acoustic cues (Ball and Müller, 2005).

In Greek, words carry one stress on one of the last three syllables (e.g. Holton et al., 1997). Greek stress is variable; the position of stress in each word is morphologically determined and is generally unpredictable phonologically (Arvaniti, 2007). Stress plays a critical role in Greek: it carries a significant functional load, to a greater extent than stress in English, since there are many pairs and even triplets of words that are only distinguished by stress location (Arvaniti, 2007). In many cases these pairs and triplets are semantically unrelated, e.g. ['poli] "city", [po'li] "much". As a matter of fact, stressing a word on the wrong syllable is one of the least tolerated mistakes a non-native speaker can make in Greek (Arvaniti, 2007).

Stress in Greek is acoustically signaled by a combination of factors. Botinis (1989) and Arvaniti (2000) showed that stressed vowels have higher amplitude than unstressed vowels and are $30 \%$ to $40 \%$ longer. However, neither duration nor amplitude are consistently greater in stressed versus unstressed vowels and syllables. Accordingly, it is argued that amplitude integral, 
a measure that combines the effect of amplitude and duration, is a more representative correlate of stress in Greek (Arvaniti, 2000; 2007) than any one single measure.

\section{Dysarthria and lexical stress}

Perceptual descriptions of stress patterning in dysarthria indicate that in dysarthric speech, the acoustic cues of stress may be employed to a lesser extent, compared to unimpaired speech. For example, given that the characteristics of slow speech rate, prolonged speech sounds and excess and equal stress are prominent in ataxic dysarthria and cerebellar disorders (Brown et al., 1970), we may expect speech output in these conditions to be characterized by a reduced differentiation between stressed and unstressed syllables due to the raised saliency of the latter, mainly as a result of their increased duration.

Most studies of suprasegmentals in dysarthria focus on the overall rhythm and timing of connected speech, on the acoustic manifestations of sentence stress, and on question vs. statement contrasts. Kim et al., one of the few studies dedicated to lexical stress (2010), investigated the acoustic cues of lexical stress in American English produced by participants with spastic dysarthria. Lexical stress was quantified by measuring intensity, duration and fundamental frequency, and by calculating the ratio of the stressed to the unstressed syllable for each of these acoustic cues. The results of the study indicated that participants with spastic dysarthria were able to convey lexical stress by making the stressed syllable more prominent through the modulation of intensity and duration but to a lesser extent than normal speakers. However, the authors did not use any perceptual data to demonstrate the ability of the dysarthric speakers to signal lexical stress. The use of pitch as a cue for stress was not consistent and this was true for both the dysarthric speakers and the normal controls. As regards the effect of stress 
position within groups, the controls used all three cues to a greater extent when stress was on the second syllable. The dysarthric group presented with the opposite pattern; word initial stress was signaled to a greater extent, a finding that can be explained by the fact that spastic dysarthria is often characterized by abrupt onset.

Beyond the area of dysarthria, difficulties with lexical stress have also been investigated in a number of different pathologies, including hearing impairment and childhood and acquired apraxia of speech (Rutter et al., 2010). In these populations atypical stress patterns can result in incorrect stress assignment and placement (see Dodd, 1976, for hearing disorders; Kent and Rosenbek, 1983, for acquired apraxia of speech). Finally, according to Rutter et al. (2010), the specific arrangement of stressed and unstressed syllables within a word seems to affect the ability to signal lexical stress in childhood apraxia of speech; it is easier for children with apraxia to produce words with a trochaic pattern rather than an iambic pattern, a finding similar to that of Kim et al. (2010) for spastic dysarthria.

In Greek, signaling the wrong stress placement is the type of lexical stress problem that would have a detrimental effect on intelligibility since there are many cases in which the location of lexical stress is the only means to disambiguate between different meanings (Arvaniti, 2007). It can be hypothesized that such errors in stress placement are the result of reduced relative acoustic prominence of stressed syllables. For a syllable to be heard as stressed it has to be more prominent than the unstressed syllable(s) in the word and, less importantly, more prominent compared to the same syllable when it is unstressed (Arvaniti, 2000). In Greek, this appears to mainly translate into longer duration and higher intensity. If these acoustic cues are not higher in the syllable intended to be produced as stressed, it is assumed that listeners will tend to not perceive it as such. On the other hand, if intensity and duration are indeed increased in stressed 
syllables but not to the same extent compared to normal speakers (as was the case in Kim et al., 2010), it is hypothesized that correct stress placement will still be signaled, although speech may sound dysrhythmic. Therefore, in terms of the acoustic stress cues, the difference between signaling wrong stress location and signaling the intended stress location in an atypical way is probably that between direction vs. degree of change of the acoustic stress cues.

The study we report on here investigated the effects of dysarthria on the realization of lexical stress in Greek during a single word production task. Of interest are the effects of dysarthria on lexical stress in terms of stress location, and the relationship between atypical use of acoustic stress cues and problems with conveying lexical stress location.

\section{Methods}

\section{Participants}

Due to the scarcity of research in Greek dysarthria, the inconsistency of diagnostic labels and the heterogeneous nature of the dysarthrias (Wenke, Theodoros, \& Cornwell, 2010), a case-based approach was chosen for this study, involving three Greek speakers with dysarthria, and two unimpaired control participants.

Information for the participants of this study is summarized in table 1. All participants were L1 Greek speakers and spoke standard Modern Greek. None of the participants with dysarthria had any evident or diagnosed cognitive, language, or speech perception problems. Based on sex and age characteristics, Anna and Maria were matched with control 1 and Chris (all names are pseudonyms) with control 2. The two unimpaired speakers were used as controls in the lexical stress identification task and in the analysis of the acoustic stress cues. Fourteen 
listeners participated in the stress identification task; nine males and five females (age range: 2732 years). They had no language production or comprehension difficulties and no known history of speech output or hearing problems, or voice pathology. None of the listeners had any specialist background knowledge in speech / language disorders or phonetics / phonology.

An initial perceptual assessment of the speech characteristics of each participant with dysarthria was conducted by the first author and two other Greek speech-language pathologists. They provided intelligibility ratings for each participant and described their deviant speech characteristics, paying particular attention to their overall speech rhythm and timing patterns and their ability to convey lexical stress. Table 1 presents the main speech characteristics for each participant with dysarthria.

\section{Table 1 about here}

\section{Data collection and analysis}

The three participants with dysarthria and the two control speakers carried out a single word repetition task that included pairs of real words differentiated only by stress location. It was assumed that the speakers with dysarthria attempted to realize each word with the intended stress pattern demonstrated in the examiner's model. These data were used in the stress identification task conducted to assess whether the signaling of the location of lexical stress at the single word level was perceptually transparent. The set of word pairs were also acoustically analyzed in order to assess the overall use of the acoustic cues of Greek lexical stress. The acoustic findings were 
compared with the results of the perception task, in order to discover the relation between perceptual effects and acoustic correlates.

\section{Single word repetition task}

The participants were asked to repeat a set of 54 words, presented by the first author in randomized order, one word at a time. The word list contained 27 pairs of segmentally identical disyllabic words differentiated only by stress location (see table 2).

\section{Table 2 about here}

\section{Lexical stress identification task}

The 14 naïve listeners were asked to listen to minimal pairs of words differing by stress only, and judge stress position for each word (either $1^{\text {st }}$ or $2^{\text {nd }}$ syllable). The word pairs were devised by the first author from the words produced by the three participants with dysarthria and the two controls. The listeners were provided with a transcription for every word pair, using the Roman alphabet, since in some cases it was hard to identify the target words in each pair due to segmental errors in the dysarthric data. The Roman alphabet was chosen over Greek orthography because the latter would have given additional clues about the meaning and therefore stress position of the word. Stimuli were presented participant by participant and the order of participants was randomized. The order of presentation for the 27 minimal stress pairs was also randomized across the five participants. 
The following is an English translation of the instructions provided to the listeners: "You will hear a number of two-word sequences produced by both normal speakers and speakers with speech difficulties due to neurological damage, and you will see the orthographic transcription of each sequence on this form. Each sequence consists of a pair of disyllabic words; each word is stressed on either the $1^{\text {st }}$ or the $2^{\text {nd }}$ syllable and the two words could have the same or different stress location. The two words in each pair are identical and the location of lexical stress is the only thing that could make them sound different. Your task is to judge the stress location of each word in every word pair by writing down " 1 " next to the word's orthographic transcription if you hear that the word is stressed on the $1^{\text {st }}$ syllable and " 2 " if the word is stressed on the $2^{\text {nd }}$ syllable. If you cannot identify the stress position in a target word, use the "?" symbol. If you wish you may replay each word sequence.”

Although the listeners were instructed that the two words in the minimal pair sequences could have the same stress pattern, i.e. they could both be of the ' $S_{1} S_{2}$ or the $S_{1}{ }^{\prime} S_{2}$ type, in reality the two target words in each word pair had a different location of lexical stress. In other words, each sequence was either ' $S_{1} S_{2} S_{1}{ }^{\prime} S_{2}(A)$ or $S_{1}{ }^{\prime} S_{2}{ }^{\prime} S_{1} S_{2}(B)$. Subsequently, the judgment of each listener for every word pair was documented using the following coding system: $A={ }^{\prime} S_{1} S_{2} S_{1}{ }^{\prime} S_{2}$, $\mathrm{B}=\mathrm{S}_{1}{ }^{\prime} \mathrm{S}_{2}{ }^{\prime} \mathrm{S}_{1} \mathrm{~S}_{2}, \mathrm{C}=\mathrm{'}_{1} \mathrm{~S}_{2}{ }^{\prime} \mathrm{S}_{1} \mathrm{~S}_{2}, \mathrm{D}=\mathrm{S}_{1} \mathrm{~S}_{2}{ }^{\prime} \mathrm{S}_{1} \mathrm{~S}_{2}, \mathrm{E}=$ ? ' $\mathrm{S}_{1} \mathrm{~S}_{2}, \mathrm{~F}=$ ? $\mathrm{S}_{1}{ }^{\prime} \mathrm{S}_{2}, \mathrm{G}=\mathrm{C}_{1} \mathrm{~S}_{2} ? \mathrm{H}=\mathrm{S}_{1}{ }^{\prime} \mathrm{S}_{2}$ ?, and finally $\mathrm{I}=?$ ?, if the listener could not identify stress location in either words in the sequence. When an answer was coded "?" it was assumed that either the stress on that word was perceived as equal on both syllables, or it was so weak that the listeners couldn't identify a difference. Following the initial coding, responses were categorized as either correct or incorrect, based on their correspondence to the intended target. Incorrect responses were categorized as either errors on ' $\mathrm{S}_{1} \mathrm{~S}_{2}$ words, on $\mathrm{S}_{1} \mathrm{~S}_{2}$ words or on both word types of the respective word pair. In that way, 
"A", "B" responses were categorized either as correct or as errors on both word types, depending on the intended lexical pattern of each word sequence, responses coded "C" were categorized as $S_{1}{ }^{\prime} S_{2}$ errors and " $D$ " responses as ' $S_{1} S_{2}$ errors. The responses of the "?" type were categorized in a similar way.

It has to be pointed out that the use of minimal stress pairs rather than single words in the stress identification task could have had an effect on the listeners' response patterns, in that the word sequence type, "A" or "B", could have affected the listeners' judgments. This possibility was explored by comparing the distributions of the listeners' judgments for the two sequences, using the chi-square $\left(\chi^{2}\right)$ tests of independence to assess whether there was a significant difference between the answer distributions of the " $\mathrm{A}$ " versus the "B" sequences in the 27 word pair set for each of the five participants. Based on the $\chi^{2}$ analysis, there was no significant effect of the sequence type on the listeners' response patterns for any of the participants (Anna: $\chi^{2}=4.739$, not significant at $\mathrm{df}=3$; Chris: $\chi^{2}=1.509$, not significant at $\mathrm{df}=2$; Maria: $\chi^{2}=1.282$, not significant at $\mathrm{df}=2$ ). In other words, in both " $\mathrm{A}$ " and "B" sequences the listeners exhibited similar patterns of lexical stress judgments.

Listener judgments were expressed in terms of their correspondence to the intended sequence, i.e. correct and incorrect, with incorrect responses categorized as either errors on ' $\mathrm{S}_{1} \mathrm{~S}_{2}$ words, on $\mathrm{S}_{1}$ ' $\mathrm{S}_{2}$ words or on both word types. Additionally, as already mentioned, all tested sequences were either of the A or B type and this pattern was likely to be noticed by the listeners at some point during the task, although they were instructed that the two words in any one word pair could have the same stress pattern. It can be assumed that, especially in the cases in which a listener had difficulty identifying the stress location in one of the two target words, he/she could 
have compared and contrasted the stress patterns in the two words in order to arrive at a stress location judgment.

Listener performance was documented by comparing the listeners' replies to the speakers' intended lexical stress patterns and calculating the percentage of correct and incorrect identification of stress location for the whole data set and for each of the 27 word pairs in every speaker. Additionally, the types of error patterns were identified and the speakers with dysarthria were compared to the controls. The performance of the listener group in the stress identification task also included the analysis of the patterns of across listener agreement for every word sequence and for the whole set of word pairs produced by each participant. Across listener consistency was estimated by a) calculating the percentage of the listeners that agreed on the lexical stress pattern of each word pair, irrespective of their response and b) by using Randolph's (2005) free-marginal multirater kappa. Free-marginal kappa is a chance-adjusted measure of agreement for any number of raters assigning cases to nominal categories; it is appropriate when one or more marginals are not fixed, i.e. for agreement studies in in which the raters are not forced to assign a certain number of cases to each category (Randolph, 2005). For the use of this agreement index the number of categories should be carefully considered. According to Randolph (2005), it is suggested to use as few categories as possible, since using more categories than is theoretically justified will spuriously inflate the metric's value. In this study, across listener consistency was calculating using a maximum of four rating categories: correct judgments, errors on ' $\mathrm{S}_{1} \mathrm{~S}_{2}$ words, on $\mathrm{S}_{1}{ }^{\prime} \mathrm{S}_{2}$ words or on both word types. The values of multirater $\kappa_{\text {free }}$ can range from -1.0 to 1.0, with -1.0 indicating perfect disagreement below chance, 0.0 indicating agreement equal to chance, and 1.0 indicating perfect agreement above chance. A rule of thumb is that a kappa of 0.7 or above indicates adequate interrater agreement (Randolph, 
2005). However, the interpretation of the kappa statistic certainly depends on what exactly is being rated and thus, conclusions about agreement adequacy in the dysarthric data should be made cautiously and they should also be based on the agreement ratings for the data produced by the control speakers.

The findings of the stress identification task are further discussed taking into account the acoustic measurements of the lexical stress cues in an attempt to shed some light on the relation between atypical patterns of use of the acoustic correlates of stress and their effects on the signaling of lexical stress location.

\section{Acoustic analysis of lexical stress}

All audio recordings were made using a solid state compact flash recorder (Marantz PMD660) and a condenser microphone (AKG C1000S). The microphone was placed in a shock mount and positioned at about $10 \mathrm{~cm}$ from the mouth of the speaker at a 45 degree angle. Samples were directly digitized at a sampling rate of $44.1 \mathrm{kHz}$ with 16-bit quantization and stored as WAV files. The audio recording were copied to a laptop computer and re-sampled at $22.050 \mathrm{kHz}$ for acoustic analysis in the acoustic software package Praat, version 5.3.39 (Boersma and Weenink, 2012).

In order to assess the use of the acoustic cues of Greek lexical stress, the 54 disyllabic words produced by the three dysarthric speakers and the two controls were extracted and saved as individual files. Speech pressure waveforms and wide-band spectrograms were generated by Praat and each word realization was phonetically transcribed and segmented into syllables and sounds using the acoustic segmentation criteria outlined in Turk, Nakai and Sugahara (2006). 
Word, syllable and sound boundaries were identified and each word was annotated into a Text Grid object. Using these data, the phonetic mechanism of stress was captured by means of a multi-dimensional analysis that included vowel intensity and duration. Due to insufficient signal quality, several of the pairs were excluded from the measurement of the acoustic stress cues. In Chris' data, duration and intensity were calculated only at the syllable level because it was not always possible to identify acoustic boundaries within syllables.

\section{Duration and intensity}

From the Text Grid objects, vowel, syllable and word durations were measured in seconds. Intensity contours were generated in Praat and mean values for each vowel, syllable and word were obtained in $\mathrm{dB}$. The original intensity measurements were normalized to cancel out differences brought about by both accidental changes and by the fact that some speakers may naturally speak louder than others. Twenty-two word pairs were analyzed for Anna, 21 for Maria and 25 for Chris.

Although Arvaniti $(2000,2007)$ argues that amplitude integral, a measure that combines the effect of amplitude and duration, is a more representative correlate of stress in Greek, the present study investigated each acoustic cue independently, since it is theoretically possible for duration and intensity cues to be differentially affected in dysarthria. It was therefore important to take their relative contribution into account. Following Kim et al. (2010), the prominence relationship between stressed and unstressed syllables was captured by two acoustic metrics that indicate the direction of vowel duration and intensity changes due to stress.

Duration ratio (within and across words) provides a measure of stress strength in terms of vowel duration: Duration ratio = duration of stressed vowel / duration of unstressed vowel. 
The metric allows for syntagmatic and paradigmatic comparisons; i.e. it can be used to compare the stressed and unstressed vowels in each word, and the stressed and unstressed realization of the same vowel in the two members of each minimal stress pair. If the stressed member has a certain degree of prominence due to its duration, compared to its unstressed counterpart, a value higher than one results. Given that in our data the two syllables and vowels in each word are not identical, we cannot necessarily expect that a value greater than one in within words comparisons would necessarily imply a more prominent stressed vowel in terms of duration. However, it is possible to assess the use of duration as a cue for stress signaling within words by comparing the data from each dysarthric participant to the respective control speaker. Intensity ratio captures stress strength in terms of vowel intensity: Intensity ratio = intensity of stressed vowel / intensity

of unstressed vowel. A value higher than one indicates a higher intensity component of the vowel in the stressed syllable.

\section{Findings}

Overall, in the lexical stress identification task data from 27 word sequences judged by the 14 listeners, for a total of 378 ratings, were analyzed for each of the five participants. Anna and Maria were compared to control 1 and Chris was compared to control 2. The listeners identified the target lexical stress patterns in all stimuli produced by the control speakers with $100 \%$ accuracy.

Anna

Lexical stress identification task 
The listeners had marked difficulties identifying stress location in Anna's minimal word pairs, particularly in $\mathrm{S}_{1}$ ' $\mathrm{S}_{2}$ words. According to the overall distribution of the listeners' responses presented in table 4, the listener group was able to correctly identify Anna's intended lexical stress pattern with only $25 \%$ success (95/378). In $372 / 378$ cases, the listeners were able to provide a stress location judgment, irrespective of accuracy. Moreover, most of the listeners' mistakes involved only one of the two members of the word sequence (267/283, i.e. $94 \%)$. Most errors (253/283, i.e. $89.3 \%)$, involved the selection of the sequence " $C$ " $\left({ }^{\prime} S_{1} S_{2}\right.$ ' $\left.S_{1} S_{2}\right)$ even though none of the word pairs had this as the target sequence. In other words, the listeners were strongly biased towards a trochaic interpretation of Anna's output. Overall and including replies of the "?" type, the listener group had difficulty with $\mathrm{S}_{1}{ }^{\prime} \mathrm{S}_{2}$ words (they either misidentified $\mathrm{S}_{1}{ }^{\prime} \mathrm{S}_{2}$ targets as ' $\mathrm{S}_{1} \mathrm{~S}_{2}$, or they could not identify at all which syllable carried the lexical stress) in 258/378 word sequence ratings (68\%). The remaining error patterns were much more rare; the listeners judged $9 / 378$ word sequences as $\mathrm{S}_{1}{ }^{\prime} \mathrm{S}_{2} \mathrm{~S}_{1}{ }^{\prime} \mathrm{S}_{2}$, i.e. with both words having an iambic rhythm, and in 16/378 cases they made incorrect judgments on both members of the word sequence (in 15/16 cases they actually heard a lexical stress pattern which was the reverse of the one intended by the dysarthric speaker, i.e. a word sequence of the "A" type was judged as "B" and vice versa). Table 5 presents the stress location judgments of the listener group for each individual word pair.

Table 3 about here

Table 4 about here

Table 5 about here 
Listener agreement shows a clear inconsistency in the listener judgments. Overall, Randolph's free-marginal multirater kappa had a value of 0.622 for Anna's word sequence set, which is somewhat lower than the 0.7 limit above which interrater agreement is generally deemed adequate (see table 5). Across word sequences, multirater $\kappa_{\text {free }}$ ranged from 0.018 , which indicates almost chance agreement, to 1 (perfect agreement above chance). The listener agreement, as well as listener accuracy, for Anna's data, indicates that her use of acoustic cues to signal stress was problematic.

\section{Perceptual signaling of lexical stress and acoustic correlates}

The relationship between problems with conveying lexical stress location and the use of acoustic stress cues in Anna's data was explored at a case-by-case level by looking at the correspondence between the acoustic metrics and the listener judgment patterns in individual word pairs. To that end, 21 word pairs produced by Anna and the control speaker were analyzed (see tables 6 and 7). Vowel duration and intensity ratios, both within and across words, were used as acoustic metrics of the relative prominence of stressed and unstressed syllables in each word pair. This analysis looked at the relationship between problems with the direction rather than the degree of duration and intensity changes and error judgments of lexical stress location. Ratio values lower than one would signal a more prominent unstressed vowel in terms of duration and intensity.

Table 6 about here

Table 7 about here 
As evident from table 6, the comparison between error patterns and atypical ratio values in Anna's data revealed two main tendencies. The word sequences that elicited a higher number of incorrect listener responses (which were mainly $\mathrm{S}_{1}$ ' $\mathrm{S}_{2}$ errors) tended to have: a) a duration ratio $<1$ in the $S_{1}{ }^{\prime} S_{2}$ targets and $b$ ) values $<1$ in both $1^{\text {st }}$ and $2^{\text {nd }}$ syllable duration and intensity ratios in across word comparisons. In word sequences with at least one correct listener judgment, atypical duration ratios in $\mathrm{S}_{1}{ }^{\prime} \mathrm{S}_{2}$ targets were rare and ratios lower than one in across word comparisons were found only in $1^{\text {st }}$ syllable position. In the control, $\mathrm{S}_{1}{ }^{\prime} \mathrm{S}_{2}$ duration ratios lower than one were found in only $2 / 21$ word sequences and almost all across words duration and intensity ratio metrics had a value higher than one (table 7). Overall, it appears that there is a relationship, albeit inconsistent, between the number and type of errors in the listeners' stress judgments and the direction of the vowel duration and, to a lesser extent, vowel intensity changes found in the acoustic analysis of Anna's data. However, the tendencies identified are not robust and the acoustic measurements of the lexical stress cues do not adequately explain the listener error patterns.

\section{Chris}

\section{Lexical stress identification tasks}

The listeners correctly identified the target stress patterns from Chris's output with almost 90\% accuracy (337/378 responses) (see table 8). All errors (41 responses; 10.85\%) involved the misidentification of stress location in only one of the two members of the word pair, with misidentifications of iambic sequences as trochaic being clearly more prevalent (33/41). The selection of the "C" sequence was the most frequent error type (23/41). The fact that the 
listeners' performance was not at $100 \%$ accuracy, as it was for the control speakers, indicates that Chris did have some problems with conveying the intended stress pattern in some of the word pairs. There is some inconsistency in listener agreement, although perfect inter-listener agreement was found for a majority of the word pairs (16/27); Randolph's free-marginal multirater kappa had a mean value of 0.791 , ranging from 0.192 to 1 . Table 9 presents the stress location judgments of the listener group and the interrater agreement across the fourteen listeners for each of Chris's word pairs.

\section{Table 8 about here}

\section{Table 9 about here}

\section{Perceptual signaling of lexical stress and acoustic correlates}

In Chris' case, the comparison between the acoustic metrics and the listener judgment patterns for each individual word pair did not reveal any clear relationship between perceptual and acoustic data. As evident in table 10, the acoustic stress metrics do not adequately explain the error judgments found in several of his word pairs and the fact that $S_{1}{ }^{\prime} S_{2}$ targets were more susceptible to misidentification; atypical duration and intensity ratios were not more frequent in the word sequences that presented with the higher number of judgment errors. However, Chris had more atypical duration and intensity ratios overall than the control speaker (see tables 10 and $11)$. 


\section{Table 11 about here}

\section{Maria}

\section{Lexical stress identification task}

The listener group was able to correctly identify Maria's attempted lexical stress patterns with about $88 \%$ success $(332 / 378)$ (see table 12$)$. In most of the error responses, the listeners were able to provide a stress location judgment, albeit inaccurately. Replies of the "?" type constituted $31.5 \%$ of total errors (11/35). Errors involved only one of the two members of a given word sequence and instances of stress reversal were not documented. Most mistakes (32/46) were made on $\mathrm{S}_{1}{ }^{\prime} \mathrm{S}_{2}$ targets, twenty-six of which involved the selection of the "C" sequence ( $\mathrm{S}_{1} \mathrm{~S}_{2}$ ' $\left.\mathrm{S}_{1} \mathrm{~S}_{2}\right) . \mathrm{S}_{1}$ ' $\mathrm{S}_{2}$ errors were also present, but they were less frequent overall (14/46). Table 13 presents the listener group's stress location judgments for each of the twenty-seven minimal stress pairs, and inter-rater agreement. As regards listener agreement, for the whole set of the 27 word sequences, Randolph's free-marginal multirater kappa had a value of 0.732 , which is marginally higher than the 0.7 limit of adequate agreement. Across word sequences, kappa ranged from 0.192 to 1 ; listener agreement was higher than 0.7 in 18/27 word pairs and perfect in 9/27 sequences.

Table 12 about here

Table 13 about here 
Overall, the perceptual data indicated that Maria did not have any marked problems with the signaling of lexical stress at the single word level. However, the acoustic stress metrics did not sufficiently explain all the manifested patterns of listener error judgments in the stress identification task. This is demonstrated in the case-by-case analysis of the relationship between the acoustic stress metrics of vowel duration and intensity and the listener judgment patterns in individual word pairs for Maria and control 1 (tables 14 and 7, respectively). However, in word pairs that elicited errors in stress judgments, there was a higher number of duration and intensity ratios with atypical values, $(<1)$ compared to the word pairs with no incorrect listener responses. [ðrfni], the word sequence that elicited by far the most $\mathrm{S}_{1}{ }^{\prime} \mathrm{S}_{2}$ errors, was the only sequence with an atypical $S_{1}{ }^{\prime} S_{2}$ duration ratio value. The total number of atypical duration and intensity ratios was marginally higher in Maria, compared to the control speaker.

\section{Table 14 about here}

\section{Discussion}

Overall, the acoustic and perceptual data indicated that lexical stress was affected differently in each participant with dysarthria: although each presented with some difficulty in the patterning of stressed and unstressed syllables, each had different underlying problems that gave rise to quite distinct patterns of deviant speech characteristics. The atypical use of lexical stress cues in Anna's data obscured the prominence relations of stressed and unstressed syllables to the extent that the position of lexical stress was usually not perceptually transparent. On the other hand, Chris and Maria did not have substantial difficulties signaling lexical stress location, although listener judgments were not $100 \%$ accurate (in contrast to the control data)

Kim et al. (2010) found that English speakers with spastic dysarthria were able to signal lexical stress through prosodic modulations, and that they utilized the pitch and intensity cues to 
a greater extent in words stressed on the $1^{\text {st }}$ syllable, a finding that was attributed to the abrupt onset common in spastic dysarthria. However, the authors did not use any perceptual data to corroborate their acoustic findings. Interestingly, in the current study the perceptual analyses indicated that in all three Greek participants with dysarthria, but particularly in Anna's productions, ' $\mathrm{S}_{1} \mathrm{~S}_{2}$ targets were more impervious to error judgments of lexical stress location than $\mathrm{S}_{1}{ }^{\prime} \mathrm{S}_{2}$ targets, although the acoustic metrics did not always suggest a more extensive use of acoustic stress cues in $1^{\text {st }}$ syllable position.

The relationship between the use of acoustic stress cues and the patterns of stress location judgments found in the dysarthric data is not clear. This discrepancy between the acoustic and the perceptual data can be attributed to a number of different factors. It is possible that the analyses of this study did not entirely capture all aspects of stress signaling in Greek, since the acoustic analysis of lexical stress did not include all possible stress cues. Moreover, Chris' atypical phonation patterns and Maria's very slow rate of speech could have interfered with lexical stress signaling for these participants. Additionally, the analyses of the correspondence between the acoustic metrics and the listener judgment patterns in individual word sequences may have failed to fully capture the relationship between the perceptual and acoustic data because the acoustic metrics used expressed only the direction and not the degree of duration and intensity changes. Finally, the discrepancy between the acoustic and perceptual data could also be the result of factors other than the acoustic signal. The listeners were less successful in accurately identifying intended stress location in $\mathrm{S}_{1}{ }^{\prime} \mathrm{S}_{2}$ rather than ' $\mathrm{S}_{1} \mathrm{~S}_{2}$ targets in the dysarthric data. This higher vulnerability of $S_{1}{ }^{\prime} S_{2}$ tokens was not always supported by the acoustic analyses. This listener bias towards a trochaic interpretation of the dysarthric data may be related to input frequency effects. Although there are no studies available that examine the relative 
frequency of occurrence of the ' $S_{1} S_{2}$ and $S_{1}{ }^{\prime} S_{2}$ members of the Greek minimal stress pairs, it is possible that the ' $\mathrm{S}_{1} \mathrm{~S}_{2}$ words tend to occur more frequently in spoken Greek. If that were the case, it could be assumed that the atypical use of lexical stress cues would have more marked effects on the identification of lexical stress location in $S_{1}{ }^{\prime} S_{2}$ rather than ' $S_{1} S_{2}$ targets.

\section{Conclusions}

There is to date very little research on motor speech disorders among speakers of Greek. This study examined the acoustic and perceptual effects of dysarthria on the realization of lexical stress in Greek. Lexical stress plays a critical role in Greek, given that there are many words that are only distinguished by stress location. The results of this study have shown that Greek speakers with dysarthria can have substantial difficulties signaling lexical stress location, and these problems can be detrimental to intelligibility. Overall, this line of research contributes to our limited knowledge of the speech characteristics of dysarthria across different languages. Given that each language has unique features, cross-language research can shed new light on the analysis of disordered speech and help determine what aspects of dysarthria are languageuniversal and which are language-specific (Kent and Kim, 2003).

\section{Statement of interest}

The authors report no conflict of interest. 


\section{References}

Arvaniti, A. (2000). The phonetics of stress in Greek. Journal of Greek Linguistics, 1, 9-39.

Arvaniti, A. (2007). Greek phonetics: The state of the art. Journal of Greek Linguistics, 8, 97 208.

Ball, M. J. and Müller, N. (2005). Phonetics for communication disorders. Mahwah, NJ: Lawrence Erlbaum.

Boersma, P and Weenink, D. (2012). Praat: doing phonetics by computer. Retrieved from www.praat.org.

Botinis, A. (1989). Stress and prosodic structure in Greek: A phonological, acoustic, physiological and perceptual Study. Lund: Lund University Press.

Brown, J. R., Darley, F. L. and Aronson A. E. (1970). Ataxic dysarthria. International Journal of Neurology, 7, 302-318.

Dodd, B. (1976). The phonological system of deaf children. Journal of Speech and Hearing Disorders, 41, 185-198.

Holton, D., Mackridge, P. and Philippaki-Warburton, I. (1997). A comprehensive grammar of the Modern Greek language. London: Routledge.

Kent, R. D. and Kim, Y. J. (2003). Towards an acoustic typology of motor speech disorders. Clinical linguistics and Phonetics, 17(6), 427-445.

Kent, R. D. and Rosenbek, J. C. (1982). Prosodic disturbance and neurologic lesion. Brain and Language, 15, 259-1291.

Kim, H., Hasegawa-Johnson, M. and Perlman, A. (2010). Acoustic cues to lexical stress in spastic dysarthria. Speech Prosody $5^{\text {th }}$ international Conference, Chicago IL. 
Randolph, J. J. (2005). Free-marginal multirater kappa: An alternative to Fleiss' fixed-marginal multirater kappa. Joensuи University Learning and Instruction Symposium, Joensuu, Finland.

Rutter, B. (2008). Acoustic properties of repair sequences in dysarthric conversational speech: An interactional phonetic study. Unpublished PhD dissertation. University of Louisiana at Lafayette

Turk, A., Nakai, S. and Sugahara, M. (2006). Acoustic segment duration in prosodic research: A practical guide. In Sudhoff, S., Lenertova, D., Meyer, R., Pappert, S. Augurzky, P., Mleinek, I., Richter, N., and Schließer, J. (Ed.) Methods in Empirical Prosody Research. Berlin: Mouton de Gruyter.

Wenke, R. J., Theodoros, D., and Cornwell, P. (2010). Effectiveness of Lee Silverman Voice Treatment (LSVT) on hypernasality in non-progressive dysarthria: the need for further research. International journal of language and communication disorders, 45(1), 31-46. 


\section{Table 1}

Participants with dysarthria and control speakers

$\begin{array}{llllll}\text { Participant } & \text { Age } & \text { Sex } & \text { Medical diagnosis } & \text { Severity } & \text { General perceptual symptoms }\end{array}$

\begin{tabular}{|c|c|c|c|c|c|}
\hline Anna & 38 & $\mathrm{~F}$ & $\begin{array}{l}\text { Multiple Sclerosis } \\
\text { with Cerebellum } \\
\text { involvement }\end{array}$ & $\begin{array}{l}\text { Moderate } \\
\text { to Severe }\end{array}$ & $\begin{array}{l}\text { Slurred and slow speech, reduced } \\
\text { and equal stress, reduced } \\
\text { loudness, nasal emission; short } \\
\text { phrases and frequent pausing; } \\
\text { significantly reduced } \\
\text { intelligibility }\end{array}$ \\
\hline Chris & 45 & $\mathrm{M}$ & $\begin{array}{l}\text { Cerebellum spinal } \\
\text { Syndrome }\end{array}$ & $\begin{array}{l}\text { Mild to } \\
\text { Moderate }\end{array}$ & $\begin{array}{l}\text { Insufficient breath support and } \\
\text { coordination of breathing and } \\
\text { speech, frequent voice stoppages } \\
\text { and periods of voiceless } \\
\text { phonation; generally intact } \\
\text { prosody, but with some } \\
\text { dysrhythmia noted by one } \\
\text { examiner; marked reduction in } \\
\text { intelligibility }\end{array}$ \\
\hline Maria & 15 & $\mathrm{~F}$ & $\begin{array}{l}\text { Necrotizing } \\
\text { encephalopathy }\end{array}$ & Moderate & $\begin{array}{c}\text { Very marked articulatory } \\
\text { slowness, syllable by syllable } \\
\text { way of speaking, excess stress, } \\
\text { monotone; frequent pausing; } \\
\text { marked reduction in } \\
\text { intelligibility; generally } \\
\text { preserved lexical and sentence } \\
\text { stress }\end{array}$ \\
\hline Control 1 & 28 & $\mathrm{~F}$ & - & - & - \\
\hline Control 2 & 46 & M & - & - & - \\
\hline
\end{tabular}




\section{Table 2}

Phonetic transcription and translation of the word pairs used in the single word repetition task.

\begin{tabular}{|c|c|c|c|}
\hline ['pexni] & [pe'xni] & "frost" & "manger" \\
\hline ['perno] & [per'no] & "take" & "pass" \\
\hline$[\mathrm{pu} \kappa \mathrm{Ne}]$ & {$\left[\mathrm{pu}^{\prime} \mathrm{Ke}\right]$} & "Pleiades" & "birds" \\
\hline ['pleti] & [ple'ti] & "back" & "wide" \\
\hline ['teksi] & [te'ksi] & “class" & "taxi" \\
\hline ['tekno] & [te'kno] & "child" & "hottie" \\
\hline ['tolme] & [tol'me] & "dare, imperative" & "he/she dares" \\
\hline ['time] & [ti'me] & "honor, imperative" & "he/she honors" \\
\hline ['keli] & [ke'li] & "beauty" & "good, feminine" \\
\hline ['kote] & [ko'te] & "chicken" & "he/she chickens out" \\
\hline ['celi] & [ce'li] & "Kelly" & “cell” \\
\hline ['cime] & [ci'me] & "wave" & "ground meat" \\
\hline ['kute] & {$\left[\mathrm{ku}^{\prime} \mathrm{te}\right]$} & "box" & "stupid, plural" \\
\hline ['seli] & [se'li] & "scarf" & “crazy, feminine" \\
\hline ['sime] & [si'me] & “sign” & "near" \\
\hline ['soste] & [so'ste] & "save, imperative" & "right, plural" \\
\hline ['vete] & [ve'te] & "wadding, plural" & "passable" \\
\hline ['ðefni] & [ðe'fni] & "Daphne" & "madhouse" \\
\hline ['jele] & [je'le] & "laugh, imperative" & "he/she laughs" \\
\hline ['xezi] & [xe'zi] & "gawk" & "stupid, feminine" \\
\hline ['milo] & [mi'lo] & "apple" & "talk" \\
\hline ['monos] & [mo'nos] & "alone" & "single" \\
\hline ['nezi] & [ne'zi] & "mincing manner" & "Nazi"' \\
\hline ['løði] & [le' 'əi] & "oil"' & "the color of oil" \\
\hline ['refi] & [re'fi] & "shelf" & "stitch" \\
\hline ['ksino] & [ksi'no] & "scratch" & “sour” \\
\hline ['ksero] & [kse' ro] & "know" & “dry” \\
\hline
\end{tabular}




\section{Table 3}

Key to letter codes used for stress sequences in word pairs.

\begin{tabular}{cc}
\hline Code & Stress Sequence \\
\hline A & $\mathrm{S}_{1} \mathrm{~S}_{2}-\mathrm{S}_{1}{ }^{\prime} \mathrm{S}_{2}$ \\
$\mathrm{~B}$ & $\mathrm{~S}_{1}{ }^{\prime} \mathrm{S}_{2}-\mathrm{S}_{1} \mathrm{~S}_{2}$ \\
$\mathrm{C}$ & $\mathrm{S}_{1} \mathrm{~S}_{2}-\mathrm{S}_{1} \mathrm{~S}_{2}$ \\
$\mathrm{D}$ & $\mathrm{S}_{1}{ }^{\prime} \mathrm{S}_{2}-\mathrm{S}_{1} \mathrm{~S}_{2}$ \\
$\mathrm{E}$ & $?-\mathrm{S}_{1} \mathrm{~S}_{2}$ \\
$\mathrm{~F}$ & $?-\mathrm{S}_{1}{ }^{\prime} \mathrm{S}_{2}$ \\
$\mathrm{G}$ & $\mathrm{S}_{1} \mathrm{~S}_{2}-?$ \\
$\mathrm{H}$ & $\mathrm{S}_{1}{ }^{\prime} \mathrm{S}_{2}-?$ \\
$\mathrm{I}$ & $?-?$ \\
\hline
\end{tabular}




\section{Table 4}

Stress location judgment summary for the 14 listeners for the 27 minimal stress pairs constructed from Anna's output. The listeners' responses are categorized in terms of a) word sequence, and b) correspondence to the intended target with incorrect responses further categorized in terms of the word type that was misidentified.

\section{Listener responses}

\begin{tabular}{cccc}
\hline & A & B & Both A and B \\
A & 39 & 10 & 49 \\
B & 5 & 56 & 61 \\
C & 146 & 107 & 253 \\
D & 1 & 8 & 9 \\
E & 1 & 1 & 2 \\
G & 4 & 0 & 4 \\
Correct & 39 & 56 & $95(25.15 \%)$ \\
Errors: & 157 & 126 & $283(74.85 \%)$ \\
$\mathrm{S}_{1}{ }^{\prime} \mathrm{S}_{2}$ & 150 & 108 & $258(68.25 \%)$ \\
$\mathrm{S}_{1} \mathrm{~S}_{2}$ & 1 & 8 & $9(2.4 \%)$ \\
$\mathrm{S}_{1} \mathrm{~S}_{2}$ and $\mathrm{S}_{1}{ }^{\prime} \mathrm{S}_{2}$ & 6 & 10 & $16(4.2 \%)$ \\
Total & 196 & 182 & 378 \\
\hline
\end{tabular}

Sequence type 
Table 5

Stress location judgments for Anna, for each individual word pair judged.

\begin{tabular}{|c|c|c|c|c|c|c|c|c|c|c|c|c|c|c|}
\hline Type & Word pair & $\mathrm{A}$ & $\mathrm{B}$ & $\mathrm{C}$ & $\mathrm{D}$ & $\mathrm{E}$ & $\mathrm{G}$ & Correct & Errors & ${ }^{\prime} S_{1} S_{2}$ & $\mathrm{~S}_{1}{ }^{\prime} \mathrm{S}_{2}$ & $\begin{array}{c}\mathrm{S}_{1} \mathrm{~S}_{2} \& \\
\mathrm{~S}_{1} \mathrm{~S}_{2}\end{array}$ & Randolph's Kappa & Agreement \% \\
\hline $\mathrm{B}$ & [milo] & 0 & 14 & 0 & 0 & 0 & 0 & 14 & 0 & 0 & 0 & 0 & 1 & 100 \\
\hline $\mathrm{B}$ & {$[\mathrm{pu} K \mathrm{e}]$} & 0 & 14 & 0 & 0 & 0 & 0 & 14 & 0 & 0 & 0 & 0 & 1 & 100 \\
\hline $\mathrm{A}$ & [perno] & 12 & 0 & 1 & 0 & 0 & 1 & 12 & 2 & 0 & 2 & 0 & 0.648 & 85.71 \\
\hline B & [ksino] & 0 & 12 & 2 & 0 & 0 & 0 & 12 & 2 & 0 & 2 & 0 & 0.648 & 85.71 \\
\hline $\mathrm{A}$ & [teksi] & 7 & 0 & 6 & 0 & 0 & 1 & 7 & 7 & 0 & 7 & 0 & 0.282 & 50 \\
\hline $\mathrm{A}$ & [time] & 7 & 0 & 7 & 0 & 0 & 0 & 7 & 7 & 0 & 7 & 0 & 0.282 & 50 \\
\hline $\mathrm{B}$ & [tekno] & 1 & 6 & 6 & 1 & 0 & 0 & 6 & 8 & 1 & 6 & 1 & 0.106 & 42.86 \\
\hline $\mathrm{A}$ & [soste] & 5 & 0 & 9 & 0 & 0 & 0 & 5 & 9 & 0 & 9 & 0 & 0.34 & 64.28 \\
\hline $\mathrm{B}$ & [ksero] & 1 & 4 & 6 & 3 & 0 & 0 & 4 & 10 & 3 & 6 & 1 & 0.018 & 42.86 \\
\hline $\mathrm{A}$ & [ðefni] & 2 & 0 & 12 & 0 & 0 & 0 & 2 & 12 & 0 & 12 & 0 & 0.648 & 85.71 \\
\hline A & [pleti] & 2 & 0 & 11 & 0 & 0 & 1 & 2 & 12 & 0 & 12 & 0 & 0.648 & 85.71 \\
\hline B & [cime] & 0 & 2 & 11 & 1 & 0 & 0 & 2 & 12 & 1 & 11 & 0 & 0.487 & 78.57 \\
\hline $\mathrm{A}$ & [jele] & 2 & 1 & 10 & 0 & 0 & 1 & 2 & 12 & 0 & 11 & 1 & 0.487 & 78.57 \\
\hline B & [tolme] & 1 & 2 & 11 & 0 & 0 & 0 & 2 & 12 & 0 & 11 & 1 & 0.487 & 78.57 \\
\hline $\mathrm{A}$ & [pexni] & 1 & 0 & 13 & 0 & 0 & 0 & 1 & 13 & 0 & 13 & 0 & 0.809 & 92.86 \\
\hline $\mathrm{A}$ & [xezi] & 1 & 0 & 13 & 0 & 0 & 0 & 1 & 13 & 0 & 13 & 0 & 0.809 & 92.86 \\
\hline $\mathrm{B}$ & [kote] & 2 & 1 & 10 & 0 & 1 & 0 & 1 & 13 & 0 & 11 & 2 & 0.487 & 78.57 \\
\hline B & [kute] & 3 & 1 & 7 & 3 & 0 & 0 & 1 & 13 & 3 & 7 & 3 & 0.062 & 50 \\
\hline $\mathrm{A}$ & [celi] & 0 & 0 & 13 & 1 & 0 & 0 & 0 & 14 & 1 & 13 & 0 & 0.809 & 92.86 \\
\hline A & [leði] & 0 & 0 & 14 & 0 & 0 & 0 & 0 & 14 & 0 & 14 & 0 & 1 & 100 \\
\hline B & [nezi] & 0 & 0 & 14 & 0 & 0 & 0 & 0 & 14 & 0 & 14 & 0 & 1 & 100 \\
\hline B & [refi] & 0 & 0 & 14 & 0 & 0 & 0 & 0 & 14 & 0 & 14 & 0 & 1 & 100 \\
\hline B & [sime] & 0 & 0 & 14 & 0 & 0 & 0 & 0 & 14 & 0 & 14 & 0 & 1 & 100 \\
\hline $\mathrm{A}$ & [keli] & 0 & 1 & 13 & 0 & 0 & 0 & 0 & 14 & 0 & 13 & 1 & 0.809 & 92.86 \\
\hline $\mathrm{A}$ & [monos] & 0 & 1 & 12 & 0 & 1 & 0 & 0 & 14 & 0 & 12 & 2 & 0.648 & 85.71 \\
\hline $\mathrm{A}$ & [seli] & 0 & 2 & 12 & 0 & 0 & 0 & 0 & 14 & 0 & 12 & 2 & 0.648 & 85.71 \\
\hline B & [vete] & 2 & 0 & 12 & 0 & 0 & 0 & 0 & 14 & 0 & 12 & 2 & 0.648 & 85.71 \\
\hline
\end{tabular}




\section{Table 6}

The relationship between listener judgment errors and duration/intensity ratio metrics, both across (AW) and within words (WW) for Anna. " $\mathrm{x}$ " denotes a stressed/unstressed vowel ratio lower than 1 . The word pairs are listed in ascending order, based on the number of correct judgments.

\begin{tabular}{|c|c|c|c|c|c|c|c|c|c|c|c|c|}
\hline \multirow[t]{3}{*}{ Sequence } & \multirow[t]{3}{*}{ Correct } & \multicolumn{3}{|c|}{ Errors } & \multicolumn{4}{|c|}{ Duration ratio } & \multicolumn{4}{|c|}{ Intensity ratio } \\
\hline & & & & & \multicolumn{2}{|c|}{ WW } & \multicolumn{2}{|c|}{ AW } & \multicolumn{2}{|c|}{ WW } & \multicolumn{2}{|c|}{$\mathrm{AW}$} \\
\hline & & ${ }^{\prime} \mathrm{S}_{1} \mathrm{~S}_{2}$ & $\mathrm{~S}_{1}{ }^{\prime} \mathrm{S}_{2}$ & Both & $\mathrm{S}_{1} \mathrm{~S}_{2}$ & $\mathrm{~S}_{1}{ }^{\prime} \mathrm{S}_{2}$ & $1^{\mathrm{st}}$ & $2^{\text {nd }}$ & ${ }^{\prime} \mathrm{S}_{1} \mathrm{~S}_{2}$ & $\mathrm{~S}_{1}{ }^{\prime} \mathrm{S}_{2}$ & $1^{\mathrm{st}}$ & $2^{\text {nd }}$ \\
\hline [mo.nos] & 0 & 0 & 12 & 2 & $\mathrm{X}$ & $\mathrm{x}$ & & $\mathrm{x}$ & & $\mathrm{x}$ & & \\
\hline [ve.te] & 0 & 0 & 12 & 2 & $\mathrm{x}$ & $\mathrm{x}$ & $\mathrm{x}$ & $\mathrm{x}$ & & $\mathrm{x}$ & $\mathrm{x}$ & $\mathrm{x}$ \\
\hline [ke.li] & 0 & 0 & 13 & 1 & & $\mathrm{x}$ & $\mathrm{x}$ & & & $\mathrm{x}$ & & \\
\hline [ce.li] & 0 & 1 & 13 & 0 & & $\mathrm{x}$ & $\mathrm{X}$ & $\mathrm{x}$ & & $\mathrm{x}$ & & \\
\hline [lp.ði] & 0 & 0 & 14 & 0 & & $\mathrm{x}$ & $\mathrm{X}$ & & & $\mathrm{x}$ & & \\
\hline [ne.zi] & 0 & 0 & 14 & 0 & & $\mathrm{x}$ & & $\mathrm{x}$ & & $\mathrm{x}$ & & \\
\hline [re.fi] & 0 & 0 & 14 & 0 & & $\mathrm{x}$ & & & & $\mathrm{x}$ & & $\mathrm{x}$ \\
\hline [si.me] & 0 & 0 & 14 & 0 & $\mathrm{x}$ & & $\mathrm{x}$ & $\mathrm{x}$ & $\mathrm{x}$ & & $\mathrm{x}$ & $\mathrm{x}$ \\
\hline [ko.te] & 1 & 0 & 11 & 2 & $\mathrm{x}$ & & $\mathrm{X}$ & & & $\mathrm{x}$ & & \\
\hline [xe.zi] & 1 & 0 & 13 & 0 & & $\mathrm{x}$ & $\mathrm{X}$ & & & $\mathrm{x}$ & & \\
\hline [je.le] & 2 & 0 & 11 & 1 & & & & & & $\mathrm{x}$ & $\mathrm{x}$ & \\
\hline [tol.me] & 2 & 0 & 11 & 1 & $\mathrm{x}$ & & $\mathrm{X}$ & & & $\mathrm{x}$ & $\mathrm{x}$ & \\
\hline [ci.me] & 2 & 1 & 11 & 0 & & & & & & $\mathrm{x}$ & & \\
\hline [ple.ti] & 2 & 0 & 12 & 0 & & $\mathrm{x}$ & & & & $\mathrm{x}$ & & \\
\hline [so.ste] & 5 & 0 & 9 & 0 & $\mathrm{x}$ & & $\mathrm{X}$ & & & $\mathrm{x}$ & & \\
\hline [teksi] & 7 & 0 & 7 & 0 & & & & & & $\mathrm{x}$ & & \\
\hline [ti.me] & 7 & 0 & 7 & 0 & $\mathrm{x}$ & & & & & $\mathrm{x}$ & & \\
\hline [te.kno] & 6 & 1 & 6 & 1 & $\mathrm{x}$ & & & & & $\mathrm{x}$ & & \\
\hline [ksi.no] & 12 & 0 & 2 & 0 & & & $\mathrm{X}$ & & & & $\mathrm{x}$ & \\
\hline [mi.lo] & 14 & 0 & 0 & 0 & $\mathrm{x}$ & & & & & $\mathrm{x}$ & & \\
\hline [pu.Ke] & 14 & 0 & 0 & 0 & $\mathrm{x}$ & & $\mathrm{X}$ & & & $\mathrm{x}$ & & \\
\hline
\end{tabular}




\section{Table 7}

The relationship between listener judgment errors and duration/intensity ratio metrics, both across (AW) and within words (WW) for control 1. "x" denotes a stressed/unstressed vowel ratio lower than 1.

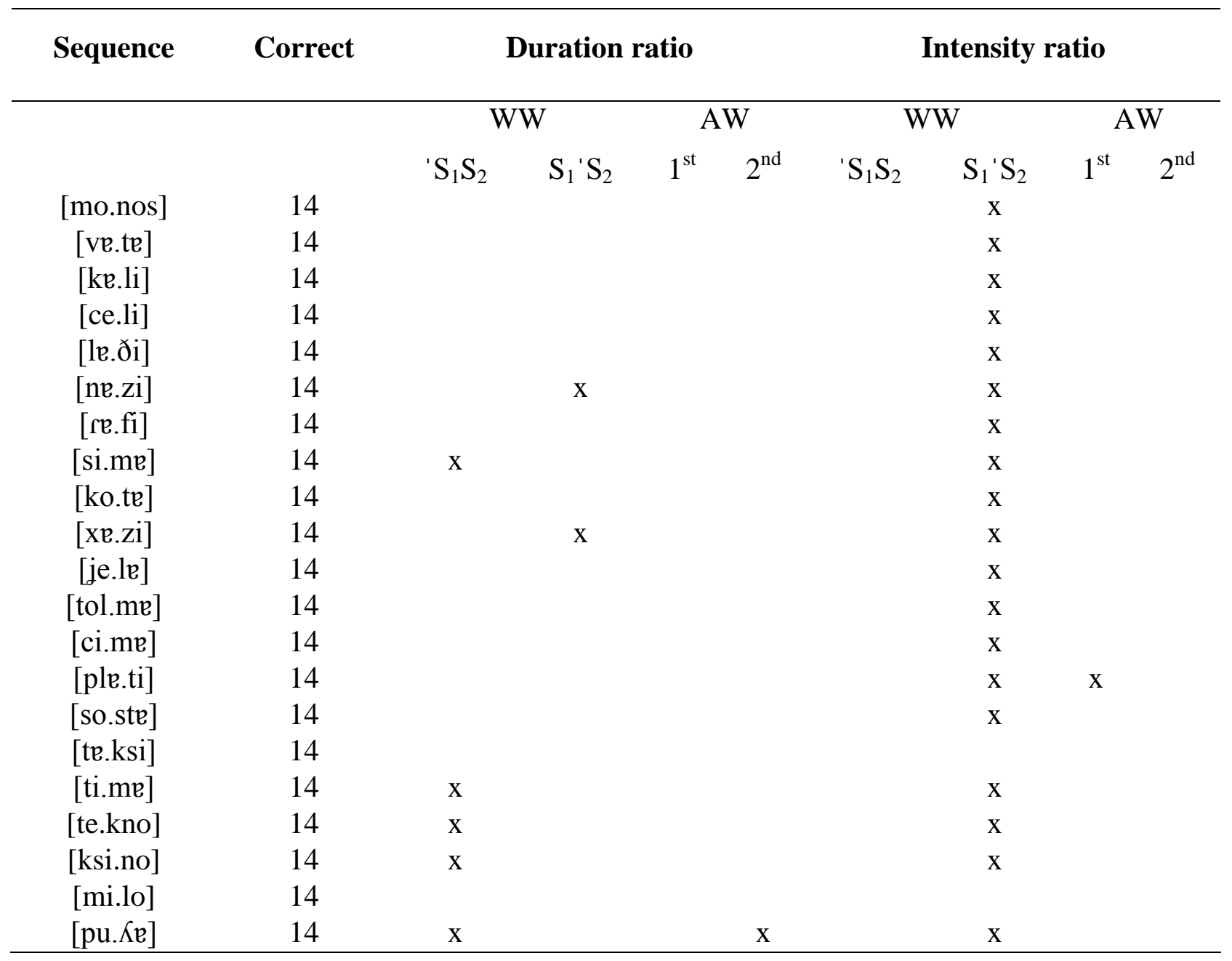




\section{Table 8}

The overall stress location judgment patterns of the 14 listeners for the 27 minimal stress pairs constructed from Chris's output.

\begin{tabular}{cccc}
\hline Listener responses & \multicolumn{2}{c}{ Sequence type } \\
\hline A & A & B & Both A and B \\
B & 161 & 0 & 161 \\
$\mathrm{C}$ & 0 & 176 & 176 \\
$\mathrm{D}$ & 15 & 8 & 23 \\
$\mathrm{E}$ & 2 & 4 & 6 \\
$\mathrm{G}$ & 0 & 6 & 6 \\
$\mathrm{H}$ & 4 & 0 & 4 \\
$\mathrm{Correct}$ & 0 & 2 & $337(89.15 \%)$ \\
Errors: $^{\prime}$ & 161 & 176 & $41(10.85 \%)$ \\
$\mathrm{S}_{1} \mathrm{~S}_{2}$ & 21 & 20 & $33(8.73 \%)$ \\
$\mathrm{S}_{1} \mathrm{~S}_{2}$ & 19 & 14 & $8(2.12 \%)$ \\
Total & 2 & 6 & 378 \\
\hline
\end{tabular}


Table 9

Stress location judgments for Chris, for each individual word pair judged.

\begin{tabular}{|c|c|c|c|c|c|c|c|c|c|c|c|c|c|c|}
\hline Type & Word pair & A & B & $\mathrm{C}$ & $\mathrm{D}$ & $\mathrm{E}$ & G & $\mathrm{H}$ & Correct & Errors & $' \mathrm{~S}_{1} \mathrm{~S}_{2}$ & $\mathrm{~S}_{1}{ }^{\prime} \mathrm{S}_{2}$ & $\begin{array}{c}\text { Randolph's } \\
\text { Kappa }\end{array}$ & Agreement $\%$ \\
\hline $\mathrm{A}$ & [celi] & 14 & 0 & 0 & 0 & 0 & 0 & 0 & 14 & 0 & 0 & 0 & 100 & 1 \\
\hline A & [milo] & 14 & 0 & 0 & 0 & 0 & 0 & 0 & 14 & 0 & 0 & 0 & 100 & 1 \\
\hline $\mathrm{A}$ & [pexni] & 14 & 0 & 0 & 0 & 0 & 0 & 0 & 14 & 0 & 0 & 0 & 100 & 1 \\
\hline $\mathrm{A}$ & [pleti] & 14 & 0 & 0 & 0 & 0 & 0 & 0 & 14 & 0 & 0 & 0 & 100 & 1 \\
\hline $\mathrm{A}$ & [refi] & 14 & 0 & 0 & 0 & 0 & 0 & 0 & 14 & 0 & 0 & 0 & 100 & 1 \\
\hline $\mathrm{A}$ & [teksi] & 14 & 0 & 0 & 0 & 0 & 0 & 0 & 14 & 0 & 0 & 0 & 100 & 1 \\
\hline $\mathrm{A}$ & [time] & 14 & 0 & 0 & 0 & 0 & 0 & 0 & 14 & 0 & 0 & 0 & 100 & 1 \\
\hline $\mathrm{A}$ & [vete] & 14 & 0 & 0 & 0 & 0 & 0 & 0 & 14 & 0 & 0 & 0 & 100 & 1 \\
\hline B & [keli] & 0 & 14 & 0 & 0 & 0 & 0 & 0 & 14 & 0 & 0 & 0 & 100 & 1 \\
\hline $\mathrm{B}$ & [ksero] & 0 & 14 & 0 & 0 & 0 & 0 & 0 & 14 & 0 & 0 & 0 & 100 & 1 \\
\hline $\mathrm{B}$ & [perno] & 0 & 14 & 0 & 0 & 0 & 0 & 0 & 14 & 0 & 0 & 0 & 100 & 1 \\
\hline $\mathrm{B}$ & [puKe] & 0 & 14 & 0 & 0 & 0 & 0 & 0 & 14 & 0 & 0 & 0 & 100 & 1 \\
\hline $\mathrm{B}$ & [sime] & 0 & 14 & 0 & 0 & 0 & 0 & 0 & 14 & 0 & 0 & 0 & 100 & 1 \\
\hline B & [soste] & 0 & 14 & 0 & 0 & 0 & 0 & 0 & 14 & 0 & 0 & 0 & 100 & 1 \\
\hline $\mathrm{B}$ & [tolme] & 0 & 14 & 0 & 0 & 0 & 0 & 0 & 14 & 0 & 0 & 0 & 100 & 1 \\
\hline $\mathrm{B}$ & [xezi] & 0 & 14 & 0 & 0 & 0 & 0 & 0 & 14 & 0 & 0 & 0 & 100 & 1 \\
\hline $\mathrm{A}$ & [kote] & 13 & 0 & 0 & 1 & 0 & 0 & 0 & 13 & 1 & 1 & 0 & 92.86 & 0.785 \\
\hline $\mathrm{A}$ & [ksino] & 13 & 0 & 0 & 1 & 0 & 0 & 0 & 13 & 1 & 1 & 0 & 92.86 & 0.785 \\
\hline $\mathrm{B}$ & [monos] & 0 & 13 & 0 & 0 & 1 & 0 & 0 & 13 & 1 & 0 & 1 & 92.86 & 0.785 \\
\hline $\mathrm{B}$ & [seli] & 0 & 13 & 0 & 0 & 0 & 0 & 1 & 13 & 1 & 1 & 0 & 92.86 & 0.785 \\
\hline $\mathrm{B}$ & [tekno] & 0 & 13 & 1 & 0 & 0 & 0 & 0 & 13 & 1 & 0 & 1 & 92.86 & 0.785 \\
\hline $\mathrm{B}$ & [nezi] & 0 & 10 & 2 & 0 & 2 & 0 & 0 & 10 & 4 & 0 & 4 & 71.43 & 0.340 \\
\hline $\mathrm{A}$ & [ðefni] & 9 & 0 & 5 & 0 & 0 & 0 & 0 & 9 & 5 & 0 & 5 & 64.29 & 0.258 \\
\hline B & [cime] & 0 & 9 & 0 & 4 & 0 & 0 & 1 & 9 & 5 & 5 & 0 & 64.29 & 0.258 \\
\hline $\mathrm{A}$ & [jele] & 7 & 0 & 5 & 0 & 0 & 2 & 0 & 7 & 7 & 0 & 7 & 50.00 & 0.192 \\
\hline A & [leði] & 7 & 0 & 5 & 0 & 0 & 2 & 0 & 7 & 7 & 0 & 7 & 50.00 & 0.192 \\
\hline $\mathrm{B}$ & [kute] & 0 & 6 & 5 & 0 & 3 & 0 & 0 & 6 & 8 & 0 & 8 & 57.14 & 0.208 \\
\hline
\end{tabular}




\section{Table 10}

The relationship between listener judgment errors and duration/intensity ratio metrics, both across (AW) and within words (WW) for Chris. " $\mathrm{x}$ " denotes a stressed/unstressed vowel ratio lower than 1.

\begin{tabular}{|c|c|c|c|c|c|c|c|c|c|c|c|}
\hline \multirow[t]{3}{*}{ Sequence } & \multirow[t]{3}{*}{ Correct } & \multicolumn{2}{|c|}{ Errors } & \multicolumn{4}{|c|}{ Duration ratio } & \multicolumn{4}{|c|}{ Intensity ratio } \\
\hline & & & & \multicolumn{2}{|c|}{ WW } & \multicolumn{2}{|c|}{ AW } & \multicolumn{2}{|c|}{ WW } & \multicolumn{2}{|c|}{ AW } \\
\hline & & $\mathrm{S}_{1} \mathrm{~S}_{2}$ & $\mathrm{~S}_{1}{ }^{\prime} \mathrm{S}_{2}$ & $\mathrm{~S}_{1} \mathrm{~S}_{2}$ & $\mathrm{~S}_{1}^{\prime} \mathrm{S}_{2}$ & $1^{\mathrm{st}}$ & $2^{\text {nd }}$ & ${ }^{\prime} \mathrm{S}_{1} \mathrm{~S}_{2}$ & $\mathrm{~S}_{1}{ }^{\prime} \mathrm{S}_{2}$ & $1^{\mathrm{st}}$ & $2^{\text {nd }}$ \\
\hline [ku.te] & 6 & 0 & 8 & $\mathrm{X}$ & & & & & & & \\
\hline [je.le] & 7 & 0 & 7 & & & & & & & & \\
\hline [le.ði] & 7 & 0 & 7 & & & & & & & $\mathrm{X}$ & $\mathrm{x}$ \\
\hline [ðe.fni] & 9 & 0 & 5 & $\mathrm{x}$ & & & & & & & \\
\hline [ci.me] & 9 & 5 & 0 & $\mathrm{x}$ & & & $\mathrm{x}$ & $\mathrm{x}$ & & & $\mathrm{x}$ \\
\hline [ne.zi] & 10 & 0 & 4 & & & & & & $\mathrm{x}$ & $\mathrm{X}$ & \\
\hline [mo.nos] & 13 & 0 & 1 & $\mathrm{x}$ & & & & & $\mathrm{x}$ & & \\
\hline [te.kno] & 13 & 0 & 1 & $\mathrm{x}$ & & & & & & & \\
\hline [ko.te] & 13 & 1 & 0 & $\mathrm{x}$ & & & & $\mathrm{x}$ & & $\mathrm{x}$ & \\
\hline [ksi.no] & 13 & 1 & 0 & & $\mathrm{X}$ & $\mathrm{x}$ & & $\mathrm{x}$ & & & \\
\hline [se.li] & 13 & 1 & 0 & & & & & & & & \\
\hline [ce.li] & 14 & 0 & 0 & & & & & & & & \\
\hline [mi.lo] & 14 & 0 & 0 & & & & & & & $\mathrm{x}$ & \\
\hline [pe.xni] & 14 & 0 & 0 & $\mathrm{x}$ & & & & & $\mathrm{x}$ & $\mathrm{X}$ & \\
\hline [ple.ti] & 14 & 0 & 0 & & & & & & $\mathrm{x}$ & $\mathrm{x}$ & \\
\hline [re.fi] & 14 & 0 & 0 & $\mathrm{x}$ & & & & & $\mathrm{X}$ & $\mathrm{x}$ & \\
\hline [te.ksi] & 14 & 0 & 0 & $\mathrm{x}$ & & & & & & & \\
\hline [ti.me] & 14 & 0 & 0 & $\mathrm{x}$ & & & & & & & \\
\hline [ke.li] & 14 & 0 & 0 & & & & & & & & \\
\hline [kse.ro] & 14 & 0 & 0 & & $\mathrm{x}$ & & & & & & \\
\hline [per.no] & 14 & 0 & 0 & & $\mathrm{x}$ & $\mathrm{x}$ & & $\mathrm{x}$ & & & \\
\hline [si.me] & 14 & 0 & 0 & & $\mathrm{X}$ & $\mathrm{x}$ & & & & & \\
\hline [so.ste] & 14 & 0 & 0 & & & & & & & & \\
\hline [tol.me] & 14 & 0 & 0 & & & & & & & & \\
\hline [xe.zi] & 14 & 0 & 0 & & & & & & & & \\
\hline
\end{tabular}




\section{Table 11}

The relationship between listener judgment errors and duration/intensity ratio metrics, both across (AW) and within words (WW) for control 2. "x" denotes a stressed/unstressed vowel ratio lower than 1 .

\begin{tabular}{|c|c|c|c|c|c|c|c|c|c|}
\hline \multirow[t]{3}{*}{ Sequence } & \multirow[t]{3}{*}{ Correct } & \multicolumn{4}{|c|}{ Duration ratio } & \multicolumn{4}{|c|}{ Intensity ratio } \\
\hline & & \multicolumn{2}{|c|}{ WW } & \multicolumn{2}{|c|}{ AW } & \multicolumn{2}{|c|}{ WW } & \multicolumn{2}{|c|}{ AW } \\
\hline & & ${ }^{\prime} \mathrm{S}_{1} \mathrm{~S}_{2}$ & $\mathrm{~S}_{1}{ }^{\prime} \mathrm{S}_{2}$ & $1^{\text {st }}$ & $2^{\text {nd }}$ & $\mathrm{S}_{1} \mathrm{~S}_{2}$ & $\mathrm{~S}_{1}{ }^{\prime} \mathrm{S}_{2}$ & $1^{\text {st }}$ & $2^{\text {nd }}$ \\
\hline [ku.te] & 14 & & & & & & & & \\
\hline [je.le] & 14 & & & & & & & & \\
\hline [le.ði] & 14 & & & & & & $\mathrm{x}$ & & \\
\hline [ðe.fni] & 14 & & & & & & & & \\
\hline [ci.me] & 14 & $\mathrm{x}$ & & $\mathrm{x}$ & & & & & \\
\hline [ne.zi] & 14 & & & & & & & & \\
\hline [mo.nos] & 14 & $\mathrm{x}$ & & & & & & & \\
\hline [te.kno] & 14 & $\mathrm{x}$ & & & & & & & \\
\hline [ko.te] & 14 & $\mathrm{x}$ & & & & & & & \\
\hline [ksi.no] & 14 & & & & & & & & \\
\hline [se.li] & 14 & & & & & & & & \\
\hline [ce.li] & 14 & $\mathrm{x}$ & & & & & & & \\
\hline [mi.lo] & 14 & & & & & & & & \\
\hline [pe.xni] & 14 & $\mathrm{x}$ & & & & & $\mathrm{x}$ & & \\
\hline [ple.ti] & 14 & & & & & & $\mathrm{x}$ & & \\
\hline [re.fi] & 14 & & & & & & $\mathrm{x}$ & & \\
\hline [te.ksi] & 14 & & & & & & & & \\
\hline [ti.me] & 14 & & & & & & & & \\
\hline [ke.li] & 14 & & & & & & & & \\
\hline [kse.ro] & 14 & $\mathrm{x}$ & & & & & & & \\
\hline [per.no] & 14 & $\mathrm{x}$ & & & & & & & \\
\hline [si.me] & 14 & & & & & & & & \\
\hline [so.ste] & 14 & & & & & & & & \\
\hline [tol.me] & 14 & $\mathrm{x}$ & & $\mathrm{x}$ & & & $\mathrm{x}$ & & \\
\hline [xe.zi] & 14 & & & & & & $\mathrm{x}$ & & \\
\hline
\end{tabular}




\section{Table 12}

The overall stress location judgment patterns of the 14 listeners for the 27 minimal stress pairs constructed from Maria's output.

\begin{tabular}{cccc}
\hline Listener responses & \multicolumn{2}{c}{ Sequence type } \\
\hline & \multicolumn{1}{c}{ B } & \\
\hline $\mathrm{A}$ & 189 & 0 & Both A and B \\
$\mathrm{B}$ & 0 & 143 & 189 \\
$\mathrm{C}$ & 14 & 12 & 143 \\
$\mathrm{D}$ & 3 & 6 & 26 \\
$\mathrm{E}$ & 0 & 4 & 9 \\
$\mathrm{~F}$ & 2 & 0 & 2 \\
$\mathrm{G}$ & 2 & 0 & 2 \\
$\mathrm{H}$ & 0 & 3 & 3 \\
$\mathrm{Correct}$ & 189 & 143 & $332(87.83 \%)$ \\
Errors: & 21 & 25 & $46(12.17 \%)$ \\
$\mathrm{S}_{1} \mathrm{~S}_{2}$ & 16 & 16 & $32(8.46 \%)$ \\
$\mathrm{S}_{1} \mathrm{~S}_{2}$ & 5 & 9 & $14(3.71 \%)$ \\
Total & 210 & 168 & 378 \\
\hline
\end{tabular}


Table 13

Stress location judgments for Maria, for each individual word pair judged.

\begin{tabular}{|c|c|c|c|c|c|c|c|c|c|c|c|c|c|c|c|}
\hline Type & Word pair & A & $\mathrm{B}$ & $\mathrm{C}$ & $\mathrm{D}$ & $\mathrm{E}$ & $\mathrm{F}$ & $\mathrm{G}$ & $\mathrm{H}$ & Correct & Errors & ${ }^{\prime} \mathrm{S}_{1} \mathrm{~S}_{2}$ & $\mathrm{~S}_{1}^{\prime} \mathrm{S}_{2}$ & $\begin{array}{l}\text { Randolph's } \\
\kappa \text { Agreement }\end{array}$ & Agreement $\%$ \\
\hline A & [jelv] & 14 & 0 & 0 & 0 & 0 & 0 & 0 & 0 & 14 & 0 & 0 & 0 & 100 & 1 \\
\hline $\mathrm{A}$ & [kote] & 14 & 0 & 0 & 0 & 0 & 0 & 0 & 0 & 14 & 0 & 0 & 0 & 100 & 1 \\
\hline A & [ksero] & 14 & 0 & 0 & 0 & 0 & 0 & 0 & 0 & 14 & 0 & 0 & 0 & 100 & 1 \\
\hline $\mathrm{A}$ & [sime] & 14 & 0 & 0 & 0 & 0 & 0 & 0 & 0 & 14 & 0 & 0 & 0 & 100 & 1 \\
\hline $\mathrm{A}$ & [vete] & 14 & 0 & 0 & 0 & 0 & 0 & 0 & 0 & 14 & 0 & 0 & 0 & 100 & 1 \\
\hline $\mathrm{A}$ & [xezi] & 14 & 0 & 0 & 0 & 0 & 0 & 0 & 0 & 14 & 0 & 0 & 0 & 100 & 1 \\
\hline $\mathrm{B}$ & [ksino] & 0 & 14 & 0 & 0 & 0 & 0 & 0 & 0 & 14 & 0 & 0 & 0 & 100 & 1 \\
\hline $\mathrm{B}$ & [time] & 0 & 14 & 0 & 0 & 0 & 0 & 0 & 0 & 14 & 0 & 0 & 0 & 100 & 1 \\
\hline $\mathrm{B}$ & [tolme] & 0 & 14 & 0 & 0 & 0 & 0 & 0 & 0 & 14 & 0 & 0 & 0 & 100 & 1 \\
\hline $\mathrm{A}$ & [celi] & 13 & 0 & 1 & 0 & 0 & 0 & 0 & 0 & 13 & 1 & 0 & 1 & 92.86 & 0.785 \\
\hline $\mathrm{A}$ & [milo] & 13 & 0 & 0 & 1 & 0 & 0 & 0 & 0 & 13 & 1 & 1 & 0 & 92.86 & 0.785 \\
\hline $\mathrm{A}$ & [nezi] & 13 & 0 & 1 & 0 & 0 & 0 & 0 & 0 & 13 & 1 & 0 & 1 & 92.86 & 0.785 \\
\hline $\mathrm{A}$ & [pexni] & 13 & 0 & 1 & 0 & 0 & 0 & 0 & 0 & 13 & 1 & 0 & 1 & 92.86 & 0.785 \\
\hline $\mathrm{A}$ & [refi] & 13 & 0 & 0 & 0 & 0 & 0 & 1 & 0 & 13 & 1 & 0 & 1 & 92.86 & 0.785 \\
\hline $\mathrm{A}$ & [teksi] & 13 & 0 & 0 & 0 & 0 & 1 & 0 & 0 & 13 & 1 & 1 & 0 & 92.86 & 0.785 \\
\hline $\mathrm{B}$ & [kute] & 0 & 13 & 0 & 1 & 0 & 0 & 0 & 0 & 13 & 1 & 1 & 0 & 92.86 & 0.785 \\
\hline $\mathrm{B}$ & [puKe] & 0 & 13 & 0 & 1 & 0 & 0 & 0 & 0 & 13 & 1 & 1 & 0 & 92.86 & 0.785 \\
\hline $\mathrm{B}$ & [seli] & 0 & 13 & 0 & 0 & 1 & 0 & 0 & 0 & 13 & 1 & 0 & 1 & 92.86 & 0.785 \\
\hline $\mathrm{A}$ & [perno] & 12 & 0 & 0 & 2 & 0 & 0 & 0 & 0 & 12 & 2 & 2 & 0 & 85.71 & 0.604 \\
\hline $\mathrm{A}$ & [soste] & 12 & 0 & 1 & 0 & 0 & 0 & 1 & 0 & 12 & 2 & 0 & 2 & 85.71 & 0.604 \\
\hline $\mathrm{B}$ & [leði] & 0 & 12 & 1 & 0 & 1 & 0 & 0 & 0 & 12 & 2 & 0 & 2 & 85.71 & 0.604 \\
\hline $\mathrm{B}$ & [pleti] & 0 & 11 & 2 & 0 & 1 & 0 & 0 & 0 & 11 & 3 & 0 & 3 & 78.57 & 0.456 \\
\hline $\mathrm{B}$ & [cime] & 0 & 10 & 4 & 0 & 0 & 0 & 0 & 0 & 10 & 4 & 0 & 4 & 71.43 & 0.340 \\
\hline $\mathrm{B}$ & [monos] & 0 & 10 & 2 & 1 & 0 & 0 & 0 & 1 & 10 & 4 & 2 & 2 & 71.43 & 0.274 \\
\hline $\mathrm{B}$ & [tekno] & 0 & 10 & 0 & 2 & 0 & 0 & 0 & 2 & 10 & 4 & 4 & 0 & 71.43 & 0.340 \\
\hline $\mathrm{B}$ & [keli] & 0 & 9 & 3 & 1 & 1 & 0 & 0 & 0 & 9 & 5 & 1 & 4 & 64.29 & 0.192 \\
\hline $\mathrm{A}$ & [ðefni] & 3 & 0 & 10 & 0 & 0 & 1 & 0 & 0 & 3 & 11 & 1 & 10 & 78.57 & 0.291 \\
\hline
\end{tabular}




\section{Table 14}

The relationship between listener judgment errors and duration/intensity ratio metrics, both across (AW) and within words (WW) for Maria. " $x$ " denotes a stressed/unstressed vowel ratio lower than 1.

\begin{tabular}{|c|c|c|c|c|c|c|c|c|c|c|c|}
\hline \multirow[t]{3}{*}{ Sequence } & \multirow[t]{3}{*}{ Correct } & \multicolumn{2}{|c|}{ Errors } & \multicolumn{4}{|c|}{ Duration ratio } & \multicolumn{4}{|c|}{ Intensity ratio } \\
\hline & & & & \multicolumn{2}{|c|}{ WW } & \multicolumn{2}{|c|}{ AW } & \multicolumn{2}{|c|}{ WW } & \multicolumn{2}{|c|}{ AW } \\
\hline & & $\mathrm{S}_{1} \mathrm{~S}_{2}$ & $\mathrm{~S}_{1}{ }^{\prime} \mathrm{S}_{2}$ & $\mathrm{~S}_{1} \mathrm{~S}_{2}$ & $\mathrm{~S}_{1}^{\prime} \mathrm{S}_{2}$ & $1^{\text {st }}$ & $2^{\text {nd }}$ & $\mathrm{S}_{1} \mathrm{~S}_{2}$ & $\mathrm{~S}_{1}{ }^{\prime} \mathrm{S}_{2}$ & $1^{\text {st }}$ & $2^{\text {nd }}$ \\
\hline [ðe.fni] & 3 & 1 & 10 & & $\mathrm{x}$ & & & & $\mathrm{x}$ & $\mathrm{x}$ & \\
\hline [ke.li] & 9 & 1 & 4 & & & & & & $\mathrm{x}$ & & \\
\hline [mo.nos] & 10 & 2 & 2 & $\mathrm{x}$ & & & & & & & \\
\hline [ci.me] & 10 & 0 & 4 & & & & & & $\mathrm{x}$ & $\mathrm{x}$ & $\mathrm{x}$ \\
\hline [te.kno] & 10 & 4 & 0 & & & & & & $\mathrm{x}$ & & \\
\hline [ple.ti] & 11 & 0 & 3 & & & & & & $\mathrm{x}$ & & \\
\hline [so.ste] & 12 & 0 & 2 & & & & & & $\mathrm{x}$ & & \\
\hline [per.no] & 12 & 2 & 0 & $\mathrm{x}$ & & $\mathrm{x}$ & & & $\mathrm{x}$ & & \\
\hline [ce.li] & 13 & 0 & 1 & & & & & & $\mathrm{x}$ & & \\
\hline [ne.zi] & 13 & 0 & 1 & & & & & & $\mathrm{x}$ & & \\
\hline [pe.xni] & 13 & 0 & 1 & & & & & & $\mathrm{x}$ & & \\
\hline [re.fi] & 13 & 0 & 1 & & & & & & $\mathrm{x}$ & & \\
\hline [mi.lo] & 13 & 1 & 0 & & & & & & & & \\
\hline [te.ksi] & 13 & 1 & 0 & $\mathrm{x}$ & & & & & $\mathrm{x}$ & & \\
\hline [pu.Ke] & 13 & 1 & 0 & $\mathrm{x}$ & & & & & & & \\
\hline [je.le] & 14 & 0 & 0 & & & & & & & & \\
\hline [ko.te] & 14 & 0 & 0 & & & & & & $\mathrm{x}$ & & \\
\hline [si.me] & 14 & 0 & 0 & $\mathrm{x}$ & & & & & & & \\
\hline [ve.te] & 14 & 0 & 0 & & & & & & $\mathrm{x}$ & & \\
\hline [xe.zi] & 14 & 0 & 0 & & & & & & $\mathrm{x}$ & & \\
\hline [ti.me] & 14 & 0 & 0 & & & & & & & & \\
\hline [tol.me] & 14 & 0 & 0 & & & & & & $\mathrm{X}$ & & \\
\hline
\end{tabular}

